neurophysiological investigation alone. ${ }^{56}$ As the number of children in the published series has been small, these results are promising but as yet inconclusive. No serial studies of computed tomography or magnetic resonance imaging in children in coma are available.

It is of great importance to those concerned with the intensive care of children that reliable predictive criteria for the development of the persistent vegetative state are established. This can be achieved only by detailed clinical, neurophysiological, and neuroradiological studies of the evolution of coma in childhood. When such coma in childhood does lead to a implications for the family, and many believe that this outcome represents a failure of

G Cole

$S$ BOYD

B KENDALL

R DINWIDDIE

D MatTheW Clinical Neurophysiology, Neuroradiology, and

Great Ormond Street,
London WCIN 3JH

1 Levy DE, Bates D, Caronna JJ, et al. Prognosis in 293-30

2 Margolis LH, Shaywitz BA. The outcome of pro longed coma in childhood. Pediatrics 1980;65: $477-83$

3 Seshia SS, Seshia MMK, Sachdeva RK. Coma in childhood. Dev Med Child Neurol 1977;19:614-28. coma in childhood: clinical variables in predictio of outcome. Dev Med Child Neurol 1983;25:493-501. Lutschg T, Pfenninger J, Ludin HP, Vassella F. Brainstem auditory evoked potentials and early treated comatose children. Am $\mathcal{f}$ Dis Child 1983 treated 137 .

6 Boyd SG, Harden Ann, Pampiglione G. Serial EEG and BAEP studies in acute encephalopathies of childhood. Electroencephalogr Clin Neurophysiol $1984 ; 58: 16$ P.

\section{Anencephaly in the United Kingdom and Republic of Ireland}

SIR, - We read with interest the paper on spina bifida and anencephaly in Scotland by Dr V Carstairs and Dr S Cole (3 November, $p$ 1182). The annual prevalence rates at birth of neural tube defects in the United Kingdom and Republic of Ireland have significantly increased and decreased at various periods throughout this century. The most recent decline is very large and has occurred when methods of prenatal diagnosis and termination of affected pregnancies have been introduced in the United Kingdom but not in the Republic of Ireland.

The table shows published and unpublished preliminary data obtained from the three registrars general in the United Kingdom and from persistent vegetative state there are profound intensive care medicine.

Departments of Neurology, Intensive Care Medicine,

Hospital For Sick Children, non-traumatic coma. Ann Intern Med 1981;94: 4 Seshia SS, Johnston B, Kasian G. Non-traumatic the director of the Central Statistics Office for the Republic of Ireland on perinatal mortality rates attributed to anencephaly. We have excluded births affected by spina bifida, owing to the difficulties of ascertaining nonfatal cases, and infants with anencephaly registered as dying after the first week of life. Trends in the prevalence of and mortality from cephaly, although differences may be apparent over certain time periods. ${ }^{12}$

It is correct, as noted by Drs Carstairs and Cole and by Leck, ${ }^{3}$ that until 1977-8 the fall in perinatal mortality from anencephaly in the Republic of Ireland compared with that in 1970-1 was negligible (estimated as $5 \%$ by Kirke) ${ }^{4}$ in contrast to falls of $39 \%, 43 \%$, and $58 \%$ in England and Wales, Northern Ireland, and Scotland respectively. The latest data, however, show that the situation has substantially altered. Between 1974 and 1982 by $52 \%, 53 \%, 91 \%$, and $81 \%$ in the Republic of Ireland, Northern Ireland, Scotland, and England and Wales respectively. Valid comparisons must take account of the differences in the availability and use of antenatal screening and termination of pregnancy for anencephaly and spina bifida in these countries. If the anencephaly rates for Scotland are adjusted to take account of the numbers terminated because of the presence of this defect, the decline in the perinatal mortality from 1974 to 1982 of $36 \%$ compares with a decline of $52^{\circ}$ in the Republic of Ireland. The large fall in the prevalence of anencephaly for the Republic of Ireland is of great interest, even though a convincing explanation cannot be put forward at present.

Medico-Social Research Board,

P N KIRKE

Dublin 2

Department of Community

Queen's
Belfast

Bower C, Hobbs M, Carney A, Simpson D. Neural ube defects in Western Australia 1966-81 and a review of Australian data $1942-81$.
Community Health $1984 ; 38: 208-13$.

Nevin NC. Neural tube defects.'Lancet 1981 ;ii:1290-1. 3 Leck I. Spina bifida and anencephaly. Br Med $\mathcal{F} 1983$; 286:1679-80.

4 Kirke P. Epidemiological clues to the causation of neural tube defects: discussion. In: Dobbing J, ed Prevention of spina bifida and other neural tube defects. London: Academic Press, 1983;191-3.

\section{Lower cranial nerve motor function in} unilateral vascular lesions of the cerebral hemisphere

SIR,-It was a pleasure to read the paper of Drs Ernest W Willoughby and Neil E Anderson (29 September, p 791). Careful spina bifida usually follow those for anenperinatal mortality from anencephaly fell

bedside observations on large numbers of patients are not common in current medical reports. They examined the motor function of the fifth cranial nerve and must have examined the corneal reflex but did not report it. There is evidence that the corneal reflex ipsilateral to the hemiparesis is absent for the first few days after the ictus and then delayed for several days. ${ }^{12}$ This usually occurs when the lesion is deep and affects the thalamus. This has never been confirmed in as large a group of patients as that studied by the authors.

With respect to the spinal accessory nerve, my experience suggests that the sternomastoid and trapezius muscles, like the upper and lower face, have different supranuclear connections. With a minimal hemiparesis, if there is any weakness in these two muscles, it will affect the trapezius contralateral to the lesion and both sternomastoids will be normal. Was the trapezius weak in the $26 \%$ of patients reported by Drs Willoughby and Anderson to have normal sternomastoid power?

With a dense hemiplegia the sternomastoid ipsilateral to the lesion and contralateral trapezius will be weak. Of these two muscles the "sensitive" or bell weather sign of an upper motor neuron lesion is, I believe, weakness of the trapezius. Although the sternomastoid may receive bilateral cerebral innervation or a doubly decussated ipsilateral innervation, as the authors and others have suggested, the trapezius, like the lower face, is probably innervated exclusively from the opposite cerebral hemisphere.

R T Ross

Section of Neurology,

University of Manitob

Winnipeg, Canada R3E 0Z3

1 Ross RT. Corneal reflex in hemisphere disease. f Neurol Neurosurg Psychiatry 1972:35:877-80. 2 Monrad-Krohn GH. Clinical examination of the nervous system. London: Lewis, 1964:207.

***Drs Willoughby and Anderson reply

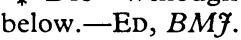

SIR,-Dr Ross raises two interesting points. The first refers to observations he has reported on depressed corneal reflexes in patients with lesions of the cerebral hemispheres. We do not have the information to answer his question about the corneal reflex ipsilateral to the hemiparesis in the patients we studied.

The second question refers to weakness of the trapezius in relation to weakness of the contralateral sternomastoid in patients with a hemiparesis. In the 25 patients in our study with normal power in the sternomastoid the trapezius on the side of the hemiparesis was weak in nine and normal in 16 . On the other hand, in the 21 patients with normal power in the trapezius the contralateral sternomastoid was weak in five and normal in 16 (table).

Relation between weakness in trapezius muscle on side of hemiparesis or hemiplegia and weakness in contralateral sternomastoid

\begin{tabular}{|c|c|c|c|c|c|c|c|c|}
\hline \multirow[b]{2}{*}{ Year } & \multicolumn{2}{|c|}{ Republic of Ireland } & \multicolumn{2}{|c|}{ Northern Ireland } & \multicolumn{2}{|c|}{ Scotland } & \multicolumn{2}{|c|}{ England and Wales } \\
\hline & No & Rate & No & Rate & No & Rate & No & Rate \\
\hline 1974 & 160 & $2 \cdot 3$ & 83 & $3 \cdot 0$ & 156 & $2 \cdot 2$ & 1045 & 1.6 \\
\hline 1975 & 173 & 2.6 & 80 & 3.0 & 140 & $2 \cdot 0$ & 915 & 1.5 \\
\hline 1976 & 136 & 2.0 & 66 & 2.5 & 89 & 1.4 & 783 & $1 \cdot 3$ \\
\hline 1977 & 150 & $2 \cdot 2$ & 61 & $2 \cdot 4$ & 66 & $1 \cdot 0$ & 693 & $1 \cdot 2$ \\
\hline 1978 & 149 & $2 \cdot 1$ & 42 & 1.6 & 57 & 0.9 & 601 & 1.0 \\
\hline 1979 & 137 & 1.9 & 47 & 1.6 & 47 & $0 \cdot 7$ & 528 & 0.8 \\
\hline 1980 & 105 & 1.4 & 48 & 1.7 & 32 & 0.5 & 411 & 0.6 \\
\hline 1981 & 109 & 1.5 & 46 & 1.8 & 19 & 0.3 & 302 & 0.5 \\
\hline 1982 & $81^{*}$ & $1 \cdot 1$ & $37^{*}$ & 1.4 & 15 & $0 \cdot 2$ & 181 & 0.3 \\
\hline 1983 & $\mathrm{NA}$ & $\mathrm{NA}$ & $22^{*}$ & 0.8 & 9 & $0 \cdot 1$ & $129^{*}$ & 0.2 \\
\hline
\end{tabular}

*Preliminary data. NA $=$ Not available.

\begin{tabular}{lccc}
\hline \multirow{2}{*}{ Sternomastoid } & \multicolumn{3}{c}{ Trapezius } \\
\cline { 2 - 4 } & Normal & Weak & Total \\
\hline Normal & 16 & 9 & 25 \\
Weak & 5 & 65 & 70 \\
Total & 21 & 74 & 95
\end{tabular}

In 81 of the 95 patients the trapezius on the side of the hemiparesis or hemiplegia and the contralateral sternomastoid were either both 